\title{
Políticas públicas en torno al fomento lector y personas en situación de discapacidad: una aproximación a la lectura estética inclusiva en Chile
}

\author{
The public policies around the promotion of reading and people with disability: \\ an approach to inclusive estetic reading in Chile
}

\author{
Solange Armijo Solís ${ }^{1}$ \\ Pontificia Universidad Católica de Chile. \\ svarmijo@uc.cl
}

\section{RESUMEN}

El objetivo del presente trabajo es analizar cómo las políticas públicas del Estado chileno se han encargado de fomentar la lectura estética en las personas en situación de discapacidad, puesto que la lectura es un derecho social. Para esto, se realizan dos estudios cualitativos complementarios: una revisión documental de las políticas vigentes, y una consulta a expertos del escenario político y académico. Los resultados develan una escasa articulación de los temas y la necesidad de redefinir los conceptos de lectura y discapacidad, junto con potenciar recursos y abrir espacios de lectura inclusivos.

Palabras claves: Lectura, fomento lector, discapacidad, inclusión.

\section{ABSTRACT}

The objective of this study is to analyze how the public politics of the Chilean Government were responsible for encouraging reading among people with disabilities, arguing that it is a social right for everyone. For that reason two studies were undertaken: documentary review of current policies and consultation with experts from academic and political circles. The results unveil a limited presence of this topic and a need to redefine the concepts of reading and disability, together with improvement of resources and opening inclusive reading spaces.

Key words: reading, promoting reading, disability, inclusion. 


\section{INTRODUCCIÓN}

La lectura como derecho social conlleva la incorporación de todas y todos a la práctica de leer. No obstante, en la era de globalización y tecnologización características del siglo XXI, esta práctica se ha redefinido, ajustándose a nuevos soportes y lenguajes (Cordón García, 2016), por lo que el acceso al libro no puede estar limitado a la materialidad del papel ni a la exclusividad de la palabra escrita, pues también se leen las imágenes, los colores, los movimientos, los sonidos, entre otros. Tal como concluye Ramírez Leyva (2009), la lectura es una actividad que no se agota ni se puede reducir solo a uno de sus elementos constitutivos.

En Chile, las investigaciones empíricas de la última década que han relacionado lectura y discapacidad han puesto el foco mayoritariamente en las dificultades que pueden experimentar estudiantes o personas en situación de discapacidad en la ejecución y procesamiento de la lectura; tanto en las distintas etapas y niveles de esta. Ejemplo de ello son los diversos estudios con fines de alfabetizar a la población sorda (Herrera Fernández, 2009, 2010, 2014; Lissi, Raglianti, Mirra, Salinas \& Cabrera, 2011); a los niños, niñas y jóvenes con discapacidad intelectual (Castillo, 2015; Miranda, 2016; Unidad de Educación Especial \& Fundación Down 21, 2008, 2012); así como también estudios que intentan describir las dificultades que suponen diagnósticos que afectan propiamente la lectura, como el caso de dislexia o retraso lector (Bravo Valdivieso, 2011; Bravo Valdivieso, Milicic Müller, Cuadro, Mejía \& Eslava, 2009; Jiménez et al., 2013). Y, en menor medida, se han desarrollado estudios respecto a diseñar medios compensatorios para la lectura de personas ciegas en soportes digitales (Correa \& Coll, 2011).

En todos estos casos, el énfasis ha estado puesto en la lectura eferente (Rosenblatt, 1993), considerando las dificultades de decodificación y/o comprensión y en la relación de ésta con los distintos tipos de diagnóstico que existen. Claramente, es innegable el aporte que han hecho dichas investigaciones en la construcción del conocimiento respecto a la discapacidad para poder determinar lineamientos de apoyo o intervenciones significativas en el área de la lectura. No obstante, son escasas las investigaciones nacionales que han vinculado el estudio de la lectura y las personas con discapacidad, entendiendo la lectura desde una arista estética (Rosenblatt, 1978), es decir, una lectura que se construye sobre un empoderamiento del lector respecto del carácter de lo que se lee. Los únicos estudios que se aproximan en cierta medida al tema, son la propuesta desarrollada por Ocampo (2016), en que se analiza la lectura desde una perspectiva inclusiva; y la investigación de Parra (2016) que devela prácticas lectoras en estudiantes con dificultades de aprendizaje.

Por tanto, esta investigación pretende aportar en la construcción de esta emergente línea investigativa, en la cual realmente se incluya a las personas en situación de discapacidad en los temas de la lectura y su fomento y que dicha articulación entre ambos temas no sea solo desde polo eferente de la lectura (Rosenblatt, 1993), ya que si bien las personas en situación de discapacidad tienen limitaciones derivadas de ella, especificamente en el acceso o procesamiento de la lectura, aun así tienen el derecho de aprovechar la lectura también desde el polo estético.

\section{MARCO TEÓRICO}

De acuerdo con el Plan Nacional de la Lectura que se encuentra en vigencia 2015-2020, la lectura es una práctica sociocultural que se desarrolla en diferentes momentos de la vida de las personas, de acuerdo a diversos propósitos y contextos; ya sea asociada al 
servicio del aprendizaje, del ocio y/o del cumplimiento de metas escolares, académicas o laborales (CNCA; MINEDUC; DIBAM, 2015). Este plan se desarrolla en alianza de importantes instituciones chilenas, como el Ministerio de Educación - en adelante Mineduc-, la Dirección de Bibliotecas, Archivos y Museos - en adelante Dibam- y el anteriormente llamado Consejo Nacional de la Cultura y las Artes -CNCA-; estas últimas dos instituciones se modifican, articulan y canalizan de mejor manera en cuanto a su quehacer en el fomento de la lectura y el libro debido a la reciente creación del Ministerio de la Cultura (MINEDUC, 2017).

Dicha definición de lectura devela un alineamiento con una conceptualización más amplia que lo instrumental y funcional para la vida, ya que considera también una dimensión recreativa, de ocio, y por tanto, la entiende también como una práctica placentera. En este sentido, la lectura por placer es entendida como una actividad voluntaria, que se encuentra al margen de las responsabilidades escolares y en la cual es posible disponer libremente del material (Dezcallar, Clariana, Cladellas, Badia, \& Gotzens, 2014); es decir, una práctica que permitirá experimentar el valor de la lectura como un referente y un proceso estético (Rosenblatt, 1978; Valdés, 2013).

Estudios nacionales indican que la lectura permite enriquecer el lenguaje tanto a nivel oral como escrito, potencia la imaginación, favorece la comprensión y permite ampliar y organizar la adquisición de información (Marchant, Lucchini, \& Cuadrado, 2007). Estudios internacionales, por su parte, destacan que los estudiantes que leen por placer alcanzan mayores niveles de rendimiento en las áreas científicas, matemática y lingüísticas (Gill, 2011) y evidencian un mayor rendimiento escolar a nivel general (Dezcallar, Clariana, Cladellas, Badia, \& Gotzens, 2014). De esta forma, disfrutar de la lectura y contar con hábitos lectores no solo aseguraría un buen rendimiento en el contexto académico, sino que también es un predictor para la motivación por el aprendizaje e incluso se correlaciona con un mejor nivel socioeconómico en la vida adulta (Ritchie \& Bates, 2013).

Las iniciativas de fomento lector desarrolladas a nivel país en los últimos 30 años, como las bibliotecas y centros de recursos de aprendizaje (Unidad de Curriculum y Evaluación, 2014), o las políticas de fomento lector y los planes derivados de ellas (Ley $\mathrm{N}^{\circ}$ 19227, 1993; CNCA, 2006, 2010, 2015) han tenido como principal objetivo aumentar los índices de lectura, mejorar las competencias lectoras y desarrollar hábitos lectores, con la visión de que la lectura es un derecho sociocultural que debe garantizarse a todos los habitantes, puesto que acorta brechas y permite crear una sociedad de personas informadas, creativas, reflexivas, críticas y participativas. Debido a esto es que progresivamente se ha ido favoreciendo la participación equitativa de comunidades minoritarias y/o grupos estratégicos: como la primera infancia, pueblos originarios, poblaciones en situación de vulnerabilidad y las personas en situación de discapacidad.

Una persona con discapacidad, en el marco legislativo chileno, se define como aquella que:

Teniendo una o más deficiencias físicas, mentales, sea por causa psíquica o intelectual, o sensoriales, de carácter temporal o permanente, al interactuar con diversas barreras presentes en el entorno, ve impedida o restringida su participación plena y efectiva en la sociedad, en igualdad de condiciones con las demás. (Ley $N^{\circ} 20422,2010$ ).

Esta definición devela un alineamiento, desde las políticas de Estado, tendiente a comprender la discapacidad desde el modelo social, donde las limitaciones que tienen las 
personas con discapacidad se deben a las barreras que los contextos suponen para ellas (Palacios, 2008). Por tanto, los deberes que el Estado chileno ha asumido en relación a la inclusión de las personas con discapacidad, están referidos a promover igualdad de oportunidades y autonomía personal, mejorar la calidad de vida, difundir información actualizada y de manera permanente sobre la prevención de discapacidades, así como también fomentar la creación de centros dedicados a prevención y rehabilitación de la discapacidad (Ley $\mathrm{N}^{\circ} 20422$, 2010). Lo que conlleva a que exista una permanente búsqueda de mejores formas de responder y valorar la diversidad junto con identificar y eliminar las barreras que generan exclusión o marginación (Echeita \& Ainscow, 2011).

La inclusión de las personas en situación de discapacidad en temas de lectura, no puede quedar circunscrita solo a una lectura funcional, instrumental o eferente (Rosenblatt, 1993), sino que se debe avanzar a entregarles verdaderas oportunidades de experimentar la lectura tambien de manera recreativa, es decir, que se empoderen como lectores, que disfruten de la experiencia completa de la lectura, que puedan elegir libremente los materiales que quieren leer y no solo leer lo que pueden o lo que se les impone, puesto que todos y todas tienen el derecho de disfrutar de la literatura y los libros, dejando que las historias envuelvan los sentidos y empoderarse de las emociones que despiertan (Bergna, 2010; Jiménez \& Flórez Romero, 2013); es decir, vivir la experiencia completa que significa la lectura.

Teniendo en consideración los elementos mencionados, el principal objetivo de la investigación es analizar cómo se ha fomentado la lectura en las personas en situación de discapacidad en Chile; para lo cual se plantean dos objetivos específicos: (1) Identificar en las políticas públicas vigentes el grado de coherencia y articulación entre los temas de discapacidad y fomento de la lectura; y (2) Determinar las barreras y oportunidades que han tenido las personas en situación de discapacidad para acceder a la lectura estética.

\section{MÉTODO}

El diseño de esta investigación es de carácter cualitativo con alcance descriptivo e interpretativo; para abordar los objetivos planteados, se realizaron dos estudios complementarios: una revisión documental de las políticas públicas vigentes a la actualidad desde el año 1990, que refieran a discapacidad y/o fomento lector, para identificar el grado de coherencia y articulación entre ambos temas. Y una consulta a expertos de amplia trayectoria tanto en el escenario político como académico, para poder determinar las principales barreras y oportunidades que han tenido, en cuanto a la lectura, las personas en situación de discapacidad.

\subsection{ESTUDIO 1: ANÁLISIS DOCUMENTAL}

En cuanto a las técnicas de producción de datos, se emplearon los criterios orientadores de impacto y actualidad (Boote \& Beile, 2005) para seleccionar las documentos; de modo que se incluyen políticas públicas de alto impacto, es decir, solo las que tienen carácter de ley o política que se encuentran vigentes hasta la actualidad, promulgadas entre los años 1990 a 2017 y que refieren a discapacidad o fomento lector (mayor detalle en anexo 1). A continuación, se muestra el tipo de documento, el tema al que pertenece y sus respectivas cantidades: 
Tabla 1. Legislación seleccionada para el corpus de análisis documental

\begin{tabular}{|l|c|c|c|}
\hline Tipo de Documento & Discapacidad & Fomento Lector & Total \\
\hline Leyes & 4 & 1 & 5 \\
\hline Políticas & - & 2 & 2 \\
\hline \multicolumn{2}{|l}{ Cantidad total de documentación revisada } \\
\hline
\end{tabular}

Fuente. Elaboración propia.

Para el análisis de los datos, se realizó análisis de contenido (López, 2002), sometiendo cada una de las políticas públicas a una revisión cruzada de conceptos, donde solo se pretendía reconocer la existencia o no de alusiones o menciones explicitas de los conceptos clave del objeto de estudio. Por lo tanto, en las políticas de discapacidad se seleccionaron como unidades de registro (López, 2002), cualquier párrafo que aludiera a fomento lector y/o lectura, y de la misma manera, párrafos que hicieran mención de las personas con discapacidad y/o la inclusión de las mismas en las políticas de fomento lector.

\subsection{ESTUDIO 2: CONSULTA A EXPERTOS}

Para la producción de datos, se formó un grupo de expertos compuesto por actores políticos, los cuales tienen una amplia experiencia en cargos de alta responsabilidad en instituciones públicas dedicadas al fomento lector o discapacidad, y por académicos con experiencia profesional e investigativa en uno o ambos temas. Inicialmente, mediante la estrategia de muestreo oportunista (Miles \& Huberman, 1994) se convocó, a través de correo electrónico a nueve informantes y posteriormente, mediante la estrategia de bola de nieve (Miles \& Huberman, 1994), es decir, contactos que establecieron los mismos entrevistados con otros expertos, se logró incorporar cuatro informantes más. La siguiente tabla resume las instituciones y áreas a las que pertenecen los 13 informantes que conforman el grupo de expertos (mayor detalle en anexo 2):

Tabla 2. Instituciones y áreas que representan los expertos consultados

\begin{tabular}{|l|c|l|}
\hline \multicolumn{1}{|c|}{ Institución } & Cantidad & \multicolumn{1}{|c|}{ Áreas que representan } \\
\hline Servicio Nacional de Discapacidad & 1 & Área Educación \\
\hline Consejo Nacional de la Cultura y las Artes & 2 & $\begin{array}{l}\text { Fondos Concursables y Plan Nacional de } \\
\text { Lectura }\end{array}$ \\
\hline Ministerio de Educación & 4 & $\begin{array}{l}\text { Biblioteca CRA; Educación Especial; Unidad } \\
\text { de Evaluación y Plan Nacional de Lectura. }\end{array}$ \\
\hline Dirección de Bibliotecas, Archivos y Museos & 2 & Fomento Lector y Director de Biblioteca. \\
\hline Pontificia Universidad Católica de Chile & 3 & Académicos (2) y Equipo de CEDETi (1). \\
\hline Biblioteca Central para Ciegos & 1 & Edición Braille. \\
\hline
\end{tabular}

Fuente. Elaboración propia. 
El instrumento empleado fue la entrevista semi estructurada (Bisquerra, 2009), de modo de contar con preguntas orientadoras elaboradas de forma abierta. Se concertó una reunión en los respectivos lugares de trabajo, donde se procedió a firmar el consentimiento y realizar la entrevista grabada en audio, las que tuvieron una duración promedio de 37 minutos, transcribiéndose en total 8 horas con 4 minutos.

Con dicho corpus, se procedió a realizar un análisis cualitativo de la información (Cáceres, 2003), donde los pasos seguidos fueron: a) pre análisis, que conlleva la identificación de conceptos en las unidades de análisis, b) determinación y definición de códigos, e c) integración y establecimiento de categorías finales. Para el análisis se empleó el software en línea Dedoose, programa que se utiliza comúnmente en investigaciones cualitativas y que permite integrar y reflexionar en torno a los datos obtenidos (Talanquer, 2014). Para validar la integración de los códigos y categorías finales, se realizó una revisión por dos jueces expertos, uno de cada tema, habiendo una aceptación y nivel de acuerdo respecto a las categorías y códigos del $80 \%$.

\section{RESULTADOS}

Los resultados de ambos estudios se presentarán de manera consecutiva. Para el primer estudio, se presenta inicialmente la revisión documental de las políticas de discapacidad y las menciones del concepto de lectura identificadas; y, a continuación, la revisión documental de las políticas de fomento y las menciones respecto al concepto de discapacidad. Posteriormente, se detallan los resultados de la consulta a expertos, describiendo tanto las barreras y oportunidades que emergen en torno a tres grandes temas: conceptos claves -lectura y discapacidad-, espacios de lectura y recursos. En este último estudio, por motivos de extensión, solo es posible incorporar una de todas las citas disponibles para representar las categorías respectivas.

\subsection{PRIMER ESTUDIO: ANÁLISIS DOCUMENTAL}

\subsubsection{Análisis de las políticas públicas de discapacidad}

Del total de cinco documentos revisados, en dos de ellos se encontraron menciones respecto a lectura, las cuales se muestran a continuación con la respectiva categoría de análisis:

Cuadro 1. Menciones a lectura en políticas de discapacidad

\section{Provisión de recursos / Ley de Igualdad de Oportunidades:}

Artículo 27.- Las bibliotecas de acceso público deberán contar con material, infraestructura y tecnologías accesibles destinadas a personas con discapacidad de causa sensorial, considerando facilidades, ajustes necesarios y prestación de servicios de apoyo para la atención de estos usuarios (Ley $\left.\mathrm{N}^{\circ} 20422,2010\right)$. 
Artículo 49.- Libérase de la totalidad de los gravámenes aduaneros la importación de los siguientes bienes: f) Elementos especiales para facilitar la comunicación, la información y la señalización para personas con discapacidad g) Equipos y material pedagógico especiales para educación, capacitación y recreación de las personas con discapacidad. h) Elementos y equipos de tecnología de la información y de las comunicaciones destinados a cualquiera de los fines enunciados en las letras anteriores (Ley $\left.\mathrm{N}^{\circ} 20422,2010\right)$.

\section{Acceso al currículum regular / Política de textos escolares:}

Desde el año 2005, las escuelas especiales del país han sido incorporadas a la entrega de textos escolares, lo que implica que los profesores que trabajan allí pueden también elegir los textos que utilizan con sus alumnos. En esta línea, el 2007 se entregó por primera vez los mismos textos escolares escritos en braille para las escuelas que atienden a niños ciegos. Para los estudiantes con discapacidad visual completa y parcial se adaptan al braille y macrotexto (letra ampliada), respectivamente, los mismos textos de estudio que reciben las escuelas y liceos regulares (Unidad de Currículum y Evaluación, 2014, pág. 9).

Fuente. Elaboración propia.

Las menciones citadas dan cuenta de una mayor preocupación por proveer de recursos principalmente de tipo material -ya sea adaptado y/o especializado- como son los textos de estudio, ediciones en Braille u otros formatos dentro de los distintos contextos -escolares y comunitarios- en que participan las personas con discapacidad, de modo que se asegure de alguna manera que los estudiantes con discapacidad cuenten con los recursos necesarios para acceder al currículum regular. Sin embargo, dichos textos o materiales de estudio no cuentan con ninguna adaptación respecto al contenido, sino que solo al formato - de la palabra escrita a formato braille o macrotexto-, por lo tanto, solo se alude a responder a las necesidades de estudiantes en situación de discapacidad derivadas de limitaciones visuales.

\subsubsection{Análisis documental de las políticas públicas de fomento lector}

De los dos documentos legislativos revisados, solo en uno de ellos se hace mención explícita a las personas con discapacidad, la cual se presenta a continuación:

Cuadro 2. Menciones a personas con discapacidad en políticas de fomento lector

Asegurar el acceso a la lectura / Política Nacional del Libro y la Lectura
Garantizar que la lectura y el acceso al libro sean utilizados como fuente de información y
aprendizaje, y para la integración de los pueblos indígenas y de las personas con capacidades
diferentes (...). Fomentar proyectos productivos que permitan la edición de libros fáciles de leer,
inclusivos y accesibles para todo público en formatos impreso, digital, audio y video. (CNCA,
2015, p. 30).

Fuente. Elaboración propia. 
En la cita se puede deducir que al señalar personas con capacidades diferentes se refiere a las personas en situación de discapacidad, lo cual, si bien no es una mención explícita, es uno de los conceptos que se han empleado en el país. En este caso, el énfasis está puesto en poder asegurar y garantizar el acceso a la lectura, entregando libros inclusivos y accesibles para todos y todas -sin distinción de su limitación- y en los distintos formatos que las tecnologías han puesto a disposición, de modo que las personas puedan tener mayores opciones de acuerdo a sus características y/o preferencias; no obstante, solo como fuente de información y de aprendizaje, lo cual da cuenta nuevamente de un énfasis hacia los contextos escolares y menos a lo recreativo, estético o literario.

En consecuencia, de un total de siete documentos revisados, solo en cuatro políticas y leyes vigentes hay menciones explícitas, desde que empiezan a tener relevancia estos temas en la agenda pública -1990-, lo cual da cuenta de una precariedad y escasa articulación de las mismas y la necesidad de hacer tanto de la lectura como de la discapacidad temas transversales a la sociedad, puesto que la preocupación central está en dar acceso a materiales de lectura, sin profundizar respecto al tipo, calidad o variedad de los mismos.

\subsection{SEGUNDO ESTUDIO: CONSULTA A EXPERTOS}

Como producto del análisis de las entrevistas, surgen tres grandes categorías que cobran mayor relevancia en la consulta a los expertos: necesidad de redefinir los conceptos de discapacidad y lectura, y limitaciones tanto en los espacios como en los recursos. Cada categoría es descrita -en palabras de los entrevistados- para posteriormente detallar las necesidades que emergen en torno a esta, de acuerdo con las consideraciones de los expertos.

\subsubsection{Redefinición de conceptos claves}

Dentro de esta temática, se describen dos conceptos esenciales: la lectura y su fomento y la inclusión de las personas con discapacidad; en ambos casos, es necesario redefinirlos desde una perspectiva más amplia para que exista un fomento lector eficiente dirigido a este grupo de personas.

\section{a. Respecto a la lectura y su fomento}

Los expertos coinciden en que las estrategias de fomento lector siempre deben considerar que la lectura refiere a una experiencia y opción personal, puesto que podría implicar diferentes beneficios o significados, donde cada lector hace su propia construcción de sentido respecto de lo que lee; es decir, tiene un fuerte carácter voluntario y es necesario que se respete como una decisión personal. En este sentido, explican que en los contextos escolares en general se otorga un excesivo énfasis respecto a qué se debe leer -lo bueno o aceptable-; cuándo se debe leer -estableciéndose rangos etarios-; y cómo se debe leer -formatos y modalidades-, consideraciones que no necesariamente responden a los gustos de los lectores en las distintas dimensiones de la práctica lectora. 
Cuadro 3. Conceptualización de la lectura y su fomento

\begin{tabular}{|l|l|}
\hline \multicolumn{2}{|l|}{ Características del fomento lector } \\
\hline $\begin{array}{l}\text { Experiencia } \\
\text { personal }\end{array}$ & $\begin{array}{l}\text { "El beneficio personal es el que va a dar cada persona al sentido que él le da } \\
\text { a la lectura, no el que yo le digo que tenga" (Experto 3 - Bibliotecas CRA). }\end{array}$ \\
\hline Carácter voluntario & $\begin{array}{l}\text { "El fomento lector yo creo que apunta al, hábito de leer, a la costumbre de la } \\
\text { lectura sistemática, pero no obligatoria" (Experto 2 -Textos escolares) }\end{array}$ \\
\hline Respetar los gustos & $\begin{array}{l}\text { "También es complejo, yo sé, como estar atento a los intereses de cada } \\
\text { estudiante, y tener un trabajo como especifico con cada uno de ellos, pero a } \\
\text { mí me parece que ese debería ser el horizonte, y adaptarse a eso en la medida } \\
\text { de las posibilidades de cada lugar" (Experto 3). }\end{array}$ \\
\hline Necesidad de reconceptualizar la lectura \\
\hline $\begin{array}{l}\text { Visión amplia y } \\
\text { diversificada de la } \\
\text { lectura }\end{array}$ & $\begin{array}{l}\text { "La lectura es desde ver una película accesible con audesc, desde ver una } \\
\text { narrativa digital, desde que te lean en voz alta, desde que te pasen un libro } \\
\text { con texturas, desde, en fin, una serie de cosas" (Experto 9 - Académico). }\end{array}$ \\
\hline
\end{tabular}

Fuente. Elaboración propia.

Por tanto, se vuelve necesario replantear y reconsiderar la lectura de una manera más amplia y diversificada y asimismo su fomento, considerando los avances tecnológicos, las diversas tipologías y/o formatos textuales, puesto que la lectura ya no puede ceñirse o reducirse solo a lo impreso -un libro físico-; a un género -narrativo-; y una percepción -visual-, volviéndose esencial que la lectura abarque todas estas distintas dimensiones y el fomento se amplíe de este modo a todos los públicos existentes.

\section{b. Respecto a la inclusión de las personas con discapacidad}

Los expertos reconocen como característica fundamental de la inclusión, la responsabilidad social frente a la misma, donde todos tienen el desafío de construir una sociedad realmente inclusiva, pensada para todos, de modo tal que cualquier actividad o iniciativa sea accesible para cualquier persona, sin segregaciones, respondiendo a las características de todas y cada una de las personas sin distinciones. Y es aquí donde la discapacidad ha hecho más notoria y evidente la diversidad, la cual debemos aprender a valorar y apreciar.

Cuadro 4. Conceptualización de la discapacidad y su inclusión

\begin{tabular}{|l|l|}
\hline \multicolumn{2}{|l|}{ Características de la inclusión } \\
\hline $\begin{array}{l}\text { Responsabilidad } \\
\text { social }\end{array}$ & $\begin{array}{l}\text { "La inclusión tiene que ver con el hacer una sociedad más inclusiva, en que } \\
\text { todos sepamos reconocer a los otros como parte de una misma sociedad" } \\
\text { (Experto 4 -Plan de lectura). }\end{array}$ \\
\hline Todos juntos & $\begin{array}{l}\text { "La inclusión tiene que ver también con que estemos todos juntos, no segregar" } \\
\text { (Experto 12 -Plan de lectura). }\end{array}$ \\
\hline $\begin{array}{l}\text { Valorar la } \\
\text { diversidad }\end{array}$ & $\begin{array}{l}\text { "Creo que parte por educar [...] valorar la maravillosa oportunidad de poder } \\
\text { relacionarnos entre todos, yo creo que eso es una labor titánica" (Experto 6 - } \\
\text { Biblioteca de Santiago). }\end{array}$ \\
\hline
\end{tabular}




\begin{tabular}{|l|l|}
\hline Necesidad de replantear la discapacidad \\
\hline $\begin{array}{l}\text { Mayor } \\
\text { visibilización }\end{array}$ & $\begin{array}{l}\text { "Hubo un esfuerzo por hacerse cargo de un tema que sabemos que no ha tenido } \\
\text { mucha visibilidad, mucha presencia, mucho protagonismo, desde las políticas } \\
\text { públicas" (Experto 4). }\end{array}$ \\
\hline $\begin{array}{l}\text { Eliminar } \\
\text { prejuicios }\end{array}$ & $\begin{array}{l}\text { "Como el estudiante tiene discapacidad, sobre todo desde lo intelectual, no } \\
\text { tiene tantas capacidades cognitivas entonces le ofrezco menos" (Experto 5 } \\
\text {-Mineduc). }\end{array}$ \\
\hline
\end{tabular}

Fuente. Elaboración propia.

Para que esto realmente pueda lograrse, es primordial que las personas con discapacidad sean más visibilizadas y consideradas en el fomento de la lectura, puesto que históricamente han estado ausentes en estos temas, debido a los prejuicios sociales que genera la desinformación y la subestimación de sus capacidades lectoras, es decir, se podría considerar innecesario fomentar la lectura en un grupo que posiblemente no tiene la capacidad de decodificar los estímulos escritos.

Por lo tanto, para lograr una verdadera inclusión de las personas con discapacidad no solo hay que ampliar el espectro de la lectura, sino que también es necesario informar y reconocer la riqueza de la discapacidad, en tanto permite dar cuenta de la diversidad, lo cual debe comenzar a reflejarse en las políticas públicas de modo que logre traducirse en prácticas sociales, culturales y lectoras realmente inclusivas.

\subsubsection{Espacios de lectura}

El segundo tema que destaca como producto del análisis de las entrevistas tiene relación con las oportunidades y barreras que suponen los espacios donde confluyen la lectura y las personas con discapacidad; se refiere tanto las características y necesidades de diversos espacios -en el sentido de lo público-, como también en espacios educativos.

\section{a. La lectura en distintos espacios}

Los expertos describen que existen determinados espacios que no cumplen con la función de fomentar la lectura para las personas con discapacidad, ya sea por temas de accesibilidad en la infraestructura o en la oferta limitada que tienen en los materiales de lectura. Estos espacios que están pensados con la única finalidad de fomentar la lectura, no son realmente inclusivos, debido a una conceptualización restringida de lo que es leer. No obstante, se reconocen ciertos progresos en los espacios que logran ser inclusivos para toda la diversidad -y no solo para las personas con discapacidad-, y ejemplo ello son las bibliotecas que se han adjudicado el sello inclusivo ${ }^{2}$.

En relación con los formatos de lectura, los espacios digitales han cobrado protagonismo como una respuesta pertinente y eficiente, abriendo nuevas posibilidades de acceso y diversidad en el fomento lector a las personas con discapacidad, lo cual se traduce en que

El Sello Chile Inclusivo es un reconocimiento que el Estado de Chile, mediante el Servicio Nacional de la Discapacidad, SENADIS, le entrega a las instituciones públicas y privadas que realicen inclusión social de las personas en situación de discapacidad. 
haya cada vez más interés por generar dispositivos, iniciativas o programas tecnológicos que respondan a las necesidades de las personas con discapacidad sensorial -visual o auditiva-. Un ejemplo de esto es la alternativa que representa la iniciativa de la DIBAM con la Biblioteca Pública Digital (http://www.bpdigital.cl/opac/?locale=es\#indice).

Cuadro 5. Características y necesidades de los espacios donde se fomenta la lectura

\begin{tabular}{|l|l|}
\hline Características de los espacios \\
\hline Oferta limitada & $\begin{array}{l}\text { "¿Cuáles no funcionan para nosotros? Todos los cafés, las teterías con libros, } \\
\text { todos estos locales en los malls, porque no tienen libros para nosotros, entonces } \\
\text { podrían funcionar si los tuvieran" (Experto 9- Académico). }\end{array}$ \\
\hline $\begin{array}{l}\text { Bibliotecas } \\
\text { inclusivas }\end{array}$ & $\begin{array}{l}\text { "yo creo que la biblioteca ha dado un gran paso cuando hemos generado } \\
\text { capacitaciones relacionadas con cómo atender a personas con enfermedades } \\
\text { mentales, aprender lengua de señas o como atender a población migrante" } \\
\text { (Experto 6 -Biblioteca de Santiago). }\end{array}$ \\
\hline $\begin{array}{l}\text { Nuevos espacios } \\
\text { digitales }\end{array}$ & $\begin{array}{l}\text { "Se ha vuelto muy importante el rol que ha jugado la tecnología en los proyectos } \\
\text { que se han financiado, siendo protagonista y elemento común de gran parte de } \\
\text { los proyectos, especialmente para personas con discapacidad sensorial" (Experto } \\
\text { 10 -Senadis). }\end{array}$ \\
\hline Necesidades para optimizar los espacios \\
\hline $\begin{array}{l}\text { Accesibilidad } \\
\text { universal }\end{array}$ & $\begin{array}{l}\text { "Que nuestras actividades sean tan inclusivas, que no tengamos que pensar y } \\
\text { decir ioh, tenemos que hacer una actividad inclusiva! o una actividad para } \\
\text { personas con discapacidad, sino que sea parte de la política permanente de la } \\
\text { biblioteca" (Experto 6). }\end{array}$ \\
\hline $\begin{array}{l}\text { Mayor difusión } \\
\text { y articulación }\end{array}$ & $\begin{array}{l}\text { "Sospecho que pocas personas ciegas están inscritas en la biblioteca pública } \\
\text { digital [...] por desconocimiento, por una falta de articulación" (Experto 9). }\end{array}$ \\
\hline
\end{tabular}

Fuente. Elaboración propia.

En consecuencia, los aspectos que son fundamentales de potenciar, de modo que los espacios funcionen, tienen que ver con la accesibilidad universal, en todos los sentidos y aspectos, para que no sea necesario hacer una actividad distinta o crear un lugar diferente para que se ofrezca lo que necesitan las personas con discapacidad, sino más bien, se optimicen y creen pensando en toda la diversidad. Además, es fundamental que se realice mayor difusión y articulación de los lugares e iniciativas que existen, para que los puedan conocer todos y todas; dicha información debe ser comunicada por distintas vías y en diversos formatos. Ya que como se señaló anteriormente, la diversidad no solo radica en la discapacidad, sino que permite dar cuenta de las necesidades de tantos otros grupos minoritarios -inmigrantes, pueblos originarios, adultos mayores, diversidad de género-, quienes también merecen las mismas oportunidades de acceso a los espacios.

\section{b. La lectura en espacios educativos}

Otro aspecto necesario de destacar son las oportunidades que ofrecen los espacios educativos en cuanto a la lectura. Se describe una gran desigualdad que se genera respecto 
al fomento lector entre los estudiantes con discapacidad que se encuentran escolarizados en escuelas especiales, versus los que asisten a escuelas regulares con proyecto de integración escolar. Para los expertos entrevistados, esta situación puede explicarse porque las escuelas especiales tienen otros focos fundamentales, desde lo asistencial hasta el desarrollo de habilidades de autonomía en la vida diaria, lo cual dejaría menos tiempo o en segundo plano la estimulación de habilidades cognitivas, dentro de las cuales estaría la práctica lectora y, más aún, el fomento de la lectura estética, placentera.

Debido a la razón que sea, claramente se genera un desmedro del fomento lector en esta opción educativa. Al contrario, los estudiantes con discapacidad escolarizados en establecimientos de enseñanza regular tienen mayores oportunidades gracias a programas específicos de fomento lector dentro de sus escuelas, como las Bibliotecas Escolares CRA que dotan con diversas colecciones bibliográficas a las escuelas con el objetivo de fomentar la lectura recreativa e informativa. Además, la lectura constituye uno de los principales ejes de la asignatura de Lenguaje y Comunicación, que tiene una alta prioridad a lo largo de toda la escolarización dentro del currículum educativo nacional.

Cuadro 6. Características y necesidades de los espacios educativos respecto a la lectura

\begin{tabular}{|c|c|}
\hline \multicolumn{2}{|c|}{ Características de los espacios educativos } \\
\hline $\begin{array}{l}\text { Escaso } \\
\text { fomento en } \\
\text { escuelas } \\
\text { especiales }\end{array}$ & $\begin{array}{l}\text { "A mí me duele, es un tema que me violenta profundamente, o sea, yo creo que hay } \\
\text { una brecha cultural..., a ver, yo soy de la idea de que la lectura rompe barreras, no, } \\
\text { eh, y el fomento lector finalmente se transforma en un puente para que la } \\
\text { discapacidad se transforme en una circunstancia no significativa en el desarrollo } \\
\text { cultural de las personas. Entonces cuando las escuelas especiales no se hacen cargo } \\
\text { de esa labor, lo que termina pasando es que los chiquillos llegan a octavo sin un } \\
\text { soporte, octavo que es hasta donde ellos llegan, sin un soporte cultural que los } \\
\text { sostenga fuera" (Experto } 9 \text {-Académico). }\end{array}$ \\
\hline $\begin{array}{l}\text { La lectura } \\
\text { como eje del } \\
\text { currículum }\end{array}$ & $\begin{array}{l}\text { "En la escuela de educación regular en general, no es que haya club de lectura } \\
\text { necesariamente, pero tienen una biblioteca, tienen lenguaje y comunicación que es } \\
\text { un eje la lectura en esa asignatura, por lo tanto, se trabaja constantemente aunque a } \\
\text { lo mejor con otras estrategias también, más o menos pertinentes pero están, en } \\
\text { escuela especial no, entonces por eso hemos puesto más fuertemente el foco en } \\
\text { ellas" (Experta } 5 \text {-Mineduc). }\end{array}$ \\
\hline \multicolumn{2}{|c|}{ Necesidades para optimizar los espacios educativos } \\
\hline $\begin{array}{l}\text { Potenciar } \\
\text { las escuelas } \\
\text { especiales }\end{array}$ & $\begin{array}{l}\text { "Se tratan de identificar por región, qué tipos de acciones desde la sociedad civil y } \\
\text { de las instituciones se hacen en lectura, y hay muy pocos, esa es la realidad, no se } \\
\text { aborda, em, casi nada, em, no hay por ejemplo, acciones que van dirigidas a escuelas } \\
\text { especiales" (Experto } 12 \text {-Plan de lectura). }\end{array}$ \\
\hline \multirow{2}{*}{$\begin{array}{l}\text { Reformular } \\
\text { el fomento } \\
\text { en las } \\
\text { escuelas } \\
\text { regulares }\end{array}$} & $\begin{array}{l}\text { "Hay poca libertad de elección de los niños entonces el gusto pasa a segundo plano, } \\
\text { aquí es por obligación, no por gusto (Experto } 13 \text {-Académico). }\end{array}$ \\
\hline & $\begin{array}{l}\text { "El tener lecturas presentadas de un modo más bien plano y con evaluaciones que } \\
\text { sabemos que siguen muy arraigadas en el sistema, los controles de lecturas que } \\
\text { tienen que ver más que nada con pillar a los alumnos, en lugar de invitarlos a } \\
\text { disfrutar de la lectura abriendo los textos" (Experto } 4 \text {-Plan de lectura). }\end{array}$ \\
\hline
\end{tabular}




\begin{tabular}{|l|l|}
\hline $\begin{array}{l}\text { Espacios de } \\
\text { las }\end{array}$ & $\begin{array}{l}\text { "Creando espacios muy acogedores, para todo tipo de estudiantes, que la colección } \\
\text { que este en la biblioteca sea lo más diversa posible, eh con actividades de mediación, }\end{array}$ \\
Escoliares & $\begin{array}{l}\text { que estén atentos a esa diversidad de estudiantes, y también yo creo con mucha } \\
\text { capacidad de escuchar yo creo, cuáles son los intereses de los estudiantes y de } \\
\text { adaptarse en base a las respuestas de ellos" (Experto 3 -Bibliotecas CRA) }\end{array}$ \\
\hline
\end{tabular}

Fuente. Elaboración propia.

En consecuencia, es necesario que se potencien las escuelas especiales, respecto a dotarlas y fortalecerlas como espacios también de fomento lector, ya que este es igual de esencial en cuanto a las habilidades de la vida diaria y como herramienta de autonomía personal y cultural; en este sentido, los expertos valoran algunos avances, como por ejemplo, el hecho de que ya a partir de este año -2018-, estas escuelas empezarán a implementar Bibliotecas Escolares CRA; lo cual representa un gran aporte en términos de acceso a materiales de lectura; no obstante, éstos son los mismos que se entregan comúnmente en las escuelas y aún no se ha considerado proveer formatos especiales o versiones adaptadas a estudiantes con discapacidad. Mientras que, en los contextos educativos en general, es imperativo que se replantee el fomento lector que se está haciendo a los estudiantes, considerando que debe ponerse fin a las lecturas impositivas que atentan contra el placer lector y a las evaluaciones que pretenden controlar el cumplimiento de la tarea y la respectiva comprensión e interpretación de esta.

\subsubsection{Recursos}

Respecto a los recursos, en primer lugar, se describen las características y necesidades de los materiales de lectura. Y, en segundo lugar, se detallan aspectos esenciales respecto a los mediadores de lectura, como recurso humano fundamental del fomento lector.

\section{a. Recursos materiales}

Un primer aspecto, que es preocupante para los expertos, es que los materiales de lectura con que cuentan las personas con discapacidad son aportes que se hacen por caridad, ya que no hay políticas que aseguren recursos, sino más bien es algo que queda sujeto a la voluntad de terceros. Esto suele suceder en contextos privados o escuelas especiales, donde se reúnen materiales de lectura mediante campañas sociales o donaciones por parte de los mismos miembros de la comunidad educativa.

Otro aspecto importante es que desde el mundo privado se están desarrollando materiales que permiten simultáneamente el uso de diversos modos de comunicación o lenguajes -texto junto a braille-, de tal forma que las personas no videntes puedan leer con personas videntes, así como también iniciativas que dan acceso a las personas sordas a obras literarias clásicas en lenguaje de señas. No obstante, estas iniciativas son puntuales y no logran el alcance que se requiere, ni en variedad ni en cobertura. 
Estudios Pedagógicos XLV, N 3: 239-260, 2019

POLÍTICAS PÚBLICAS EN TORNO AL FOMENTO LECTOR Y PERSONAS EN SITUACIÓN DE DISCAPACIDAD: UNA APROXIMACIÓN A LA LECTURA ESTÉTICA INCLUSIVA EN CHILE

Cuadro 7. Características y necesidades respecto a los recursos materiales

\begin{tabular}{|c|c|}
\hline \multicolumn{2}{|c|}{ Características de los recursos materiales } \\
\hline $\begin{array}{l}\text { Materiales por } \\
\text { caridad }\end{array}$ & $\begin{array}{l}\text { "Está muy asociado a la caridad, el acceso a la literatura en las personas con } \\
\text { discapacidad, entonces por eso tantos libros en la biblioteca de ciegos con } \\
\text { contenido más bien católico, porque está asociado al libro que uno regala, al } \\
\text { libro que a uno le dan" (Experto1-CEDETi). }\end{array}$ \\
\hline $\begin{array}{l}\text { Simultaneidad en } \\
\text { el lenguaje textual }\end{array}$ & $\begin{array}{l}\text { "Muchos de los libros que hacemos, los hacemos en tinta y braille ahora, no } \\
\text { sólo en braille, sino que viene la hoja braille, y también aquí tu abres el libro } \\
\text { y viene la hoja tinta [...] eso puede hacer que el papá la pueda leer con su hijo, } \\
\text { y puedan ir leyendo juntos, o pueda ir el profesor con el alumno" (Experto } 7 \\
\text {-Biblioteca de ciegos). }\end{array}$ \\
\hline \multicolumn{2}{|c|}{ Necesidades en cuanto a los recursos materiales } \\
\hline \multirow[t]{2}{*}{$\begin{array}{l}\text { Acceso a } \\
\text { materiales de } \\
\text { lectura }\end{array}$} & $\begin{array}{l}\text { "Hoy por hoy existe una atención creciente para que ese acceso incluya a } \\
\text { todas y todos, sin importar si se encuentra en situación de discapacidad" } \\
\text { (Experto } 8 \text {-Plan de lectura). }\end{array}$ \\
\hline & $\begin{array}{l}\text { "La lectura debería ser transversal y estar disponible al alcance de todos, el } \\
\text { acceso, para todas las personas" (Experto } 12 \text {-Plan de lectura). }\end{array}$ \\
\hline $\begin{array}{l}\text { Ofrecer } \\
\text { diversidad de } \\
\text { materiales }\end{array}$ & $\begin{array}{l}\text { "Que tengan experiencias diversas va a implicar que haya libros más sencillos, } \\
\text { otros más complejos, que haya distintos formatos, que haya distintos temas, } \\
\text { que haya distintas gráficas para ofrecer también, posibilidades de desarrollo } \\
\text { de una competencia estética amplia de parte de los niños" (Experto } 4 \text {-Plan de } \\
\text { lectura). }\end{array}$ \\
\hline $\begin{array}{l}\text { Necesidad de } \\
\text { "más" }\end{array}$ & $\begin{array}{l}\text { "Estamos más avanzados, pero se hace poco, aún es poco, hace falta en ese } \\
\text { sentido destinar más recursos más a esto" (Experto } 7 \text {-Biblioteca de ciegos). }\end{array}$ \\
\hline
\end{tabular}

Fuente. Elaboración propia.

Por lo tanto, la necesidad primaria y básica es que las personas con discapacidad puedan acceder a la lectura, que tengan a su disposición recursos materiales atingentes, y que dichos materiales sean diversos, es decir, que representen los múltiples gustos e intereses, y los diversos lenguajes o modos de comunicación, de manera que, independientemente de la discapacidad, las personas puedan acceder a ellos.

En este sentido, por parte de los expertos se reconoce un avance en la preocupación que demuestran ciertas iniciativas, proyectos o programas dirigidos a los grupos minoritarios, aunque han sido insuficientes y queda latente la necesidad de "hacer algo más" al respecto, ya que los que se han desarrollado han sido acotados en el tiempo y dirigidos a grupos específico, es decir, sin mayor impacto y con financiamiento limitado, y generalmente desarrollados por los mismos grupos que tienen la necesidad, no logrando ampliar las opciones lectoras para las personas en situación de discapacidad.

\section{b. Recursos humanos}

Los expertos destacan la figura y el rol que tiene el mediador de la lectura, describiéndolo y reconociendo en su tarea una gran responsabilidad, la que podría ir desde orientar la 
búsqueda de un determinado libro/autor, hasta mediar respecto a significados o contenidos en las lecturas; esta amplitud en las responsabilidades da cuenta de que sus roles y funciones no están claramente establecidos. En este sentido, uno de los problemas que visualizan los expertos en esta figura, es que no respete el interés genuino de un lector a causa de sus propios prejuicios como mediador, y que, en lugar de orientar y alimentar la motivación intrínseca del lector, imponga lo que a su parecer es más apropiado según la edad, el género, el tema, el reconocimiento del autor, entre otros múltiples criterios de selección de materiales de lectura.

Cuadro 8. Características y necesidades respecto a los recursos humanos

\begin{tabular}{|l|l|}
\hline Características de los mediadores de lectura \\
\hline Es un guía & $\begin{array}{l}\text { "Nadie puede obligarte a leer, pero si pueden haber personas importantes en tu } \\
\text { vida que te cautiven y te enseñen un camino en los libros, de los materiales de } \\
\text { lectura que te lleven a tener un amor por la lectura, que te haga permanecer en } \\
\text { ese estado para siempre" (Experto 12 -Plan de lectura). }\end{array}$ \\
\hline Tarea compleja & $\begin{array}{l}\text { "Yo creo que no es un rol fácil el del mediador, éticamente en general, y } \\
\text { particularmente cuando trabajan con niños en situación de discapacidad" } \\
\text { (Experto 1 -CEDETi). }\end{array}$ \\
\hline $\begin{array}{l}\text { Prejuicios frente } \\
\text { los intereses de } \\
\text { los lectores }\end{array}$ & $\begin{array}{l}\text { Pasa muchas veces que los mediadores de lectura, a veces tienen un montón de } \\
\text { ideas acerca de que es lo bueno y que es lo malo, y sobre qué es lo que el } \\
\text { estudiante tiene que aprender, que terminan como actuando en contra del } \\
\text { principio que se supone que defienden" (Experto 3 -Bibliotecas CRA). }\end{array}$ \\
\hline Necesidades respecto a los mediadores de lectura \\
\hline Debe ser lector & $\begin{array}{l}\text { "Para fomentar la lectura hay que ser lector, si no eres lector no puedes fomentar } \\
\text { la lectura, es muy difícil transmitir ese, como interés y como pasión por lo que } \\
\text { estás diciendo" (Experto 12). }\end{array}$ \\
\hline $\begin{array}{l}\text { Debe conocer } \\
\text { los usuarios y } \\
\text { las colecciones }\end{array}$ & $\begin{array}{l}\text { "va a depender del conocimiento que tenga sobre los usuarios, y mientras más } \\
\text { amplia sea la mirada del mediador y más conozca la colección que tiene y mejor } \\
\text { conozca a sus usuarios, mejor va a funcionar" (Experto 3). }\end{array}$ \\
\hline $\begin{array}{l}\text { Se necesita más } \\
\text { capacitación }\end{array}$ & $\begin{array}{l}\text { "Lo que ha estado un poco más débil es la capacitación ligada a esa entrega de } \\
\text { libros, y cómo hacemos que estas maravillas que llegan no queden encerradas } \\
\text { en la biblioteca, no queden en cajas [...] sino que hay un trabajo de mediación } \\
\text { importante (Experto 4 -Plan de lectura). }\end{array}$ \\
\hline
\end{tabular}

Fuente. Elaboración propia.

Debido a la complejidad en los roles, los expertos consideran fundamental que el mediador de la lectura sea un lector ávido, de modo que logre orientar a los lectores desde la riqueza de su propia experiencia y proyectar la pasión que profesa con su propio ejemplo. En el caso de un mediador que ejerce como bibliotecario, es fundamental que tenga un gran conocimiento tanto de los usuarios como de las colecciones que fomenta, de modo que logre articular ambos aspectos y oriente el camino hacia los libros, respetando los intereses y motivaciones que puedan tener sus usuarios. Por lo tanto, el cargo demandaría una amplia 
preparación, siendo necesario que desde las políticas públicas se asegure la capacitación y perfeccionamiento de manera permanente a esta figura, puesto que los recursos materiales junto a una eficiente y efectiva mediación, orientación o animación lograrían un impacto significativamente mayor en el aprovechamiento de los esfuerzos.

\section{DISCUSIONES Y CONCLUSIONES}

De acuerdo a los análisis desarrollados en ambos estudios, es posible destacar en primer lugar la importancia de conceptos claves, siendo preocupante la escasa articulación o conexión entre las políticas públicas de los temas estudiados -lectura y discapacidadcuando ambos han denotado un avance parecido dentro de la agenda pública a partir del año 1990, esto se evidencia en una gran dicotomía respecto de cómo se conceptualiza la lectura y la discapacidad: por ejemplo, en las legislaciones de fomento lector se emplea el término personas con capacidades diferentes, mientras que, las políticas de discapacidad refiere el término más reciente de personas en situación de discapacidad, de la misma manera sucede con el concepto de lectura, que se define de manera amplia y diversa en las políticas de fomento lector y de manera reducida o específicamente útil en los contextos de aprendizaje en las políticas de discapacidad.

Esta desconexión conceptual entre los temas no se limita al uso del lenguaje, sino que devela conceptos más profundos que tienen impacto sobre las prácticas culturales vinculadas a la lectura en este segmento de la población, puesto que una de las principales barreras para la inclusión tiene relación con políticas y normativas contradictorias (López Melero, 2011). Por lo tanto, es necesario que se redefina el concepto de lectura, diversificando y ampliándolo, de modo que las personas con discapacidad tengan cabida, es decir, que la lectura de tipo recreativa, literaria (Sanjuán Álvarez, 2011) o estética (Rosenblatt, 1993) -aquella que libera, que crea sentido, que permite descubrir la propia identidad y el mundose amplíe en sus formatos y en todas sus dimensiones para responder a la diversidad. De igual modo, es vital que la sociedad comience a educarse en temas de discapacidad, desde cómo referirse a las personas con distintos tipos de diversidades, hasta aprender a convivir con las diferencias, ya que la inclusión debe cimentarse en un proceso de humanización, respeto, participación y convivencia de todas y cada una de las personas, y en ello debe haber espacio para las distintas prácticas y formas lectoras.

Del mismo modo, en ambos estudios cobra relevancia el tema de los recursos, en el sentido de asegurar el acceso a recursos materiales para que los estudiantes en situación de discapacidad progresen en el currículum nacional prescrito, lo que da cuenta de una preocupación básica e insuficiente por parte de las legislaciones de Estado, ya que solo se apunta a dar acceso, y no ha habido políticas públicas que avancen en propender a garantizar calidad en dicho acceso, etapa todavía más necesaria en la construcción de una verdadera educación inclusiva (Cox, 2007). Es inegable que personas en situación de discapacidad tienen una deficiencia o limitación ya sea de origen intelectual, sensorial o psíquica (Ley $\mathrm{N}^{\circ} 20422$, 2010), pero no por ello debe quedar restringuido su acceso de manera libre a materiales o formatos de lectura; de igual manera, es vital que los mediadores de lectura se encuentren especificamente preparados en estos temas, de modo que tanto los recursos materiales como humanos respondan eficiente y oportunamente a las inquietudes, necesidades o intereses lectoras de este grupo. 
Una tercera dimensión, que emerge solo desde la voz de los expertos, son los espacios dedicados al fomento de la lectura, donde los hallazgos dan cuenta de una preocupación por cómo se está fomentando la lectura en los espacios educativos en que convergen los estudiantes con discapacidad. Se constata una gran falencia aún en cuanto a posibilidades de acceso a materiales en escuelas regulares e inexistentes espacios para el fomento de la lectura en las escuelas especiales. Lo cual sucede debido a que en la primera opción educativa -escuela regular con proyecto de integración-, no se están ofreciendo materiales, actividades, espacios o iniciativas que respondan a la diversidad o necesidad de estos estudiantes, solo tendrían mayores oportunidades de acceder a materiales escritos y participar en instancias de lectura gracias a las asignaturas y el currículum que cursan. Y en la segunda modalidad educativa -escuela especial-, los planes de estudio específicos para cada tipo de discapacidad (Ministerio de Educación Pública, 1990a; 1990b: 1990c; 1990d; 1990e) solo propenden al logro de la decodificación o lectura instrumental (Rosenblatt, 1993), pero en ninguno de los casos implica necesariamente que se estén creando estudiantes con hábitos, motivación y placer lector del que atraviesa y perdura en la vida. Problema que puede generalizarse a todos los estudiantes, ya que estudios nacionales recientes concluyen que si bien los estudiantes chilenos han mejorado sus índices en desempeño lector, aún los niveles de comprensión y motivación lectora son bajos, en comparación con países que tienen un nivel desarrollo económico parecido (Orellana \& Baldwin, 2016).

En consecuencia, es preciso recalcar que independiente de la modalidad educativa en que estén escolarizados los estudiantes con discapacidad, las políticas públicas deben propender y asegurar igualdad de oportunidades de acceso a la lectura, como un derecho de equidad, donde el estudiante tenga la posibilidad de leer lo que desee (Merino Risopatrón, 2011), con recursos humanos -mediadores o profesores- que guíen y aporten a la construcción de lectores motivados, informados y críticos, que cuenten con recursos materiales adecuados para ofrecer de acuerdo a las características y nivel lector de cada uno de los estudiantes, que genere espacios de respeto por los intereses de los lectores y logre encaminar a los lectores en formación por la literatura, la información y el mundo del conocimiento.

Una gran oportunidad para esto, son los espacios digitales creados por la tecnología, que permite múltiples opciones de acceso a la información, menor costo respecto a tiempo y recursos -en comparación a formatos físicos-; por ejemplo, un libro que esté en formato accesible de texto a voz solo requiere acceso a internet, a diferencia de si se imprime en braille -que es mucho más caro-, y se le entrega la misma posibilidad de acceso a la información a las personas con discapacidad visual. De la misma manera, las diversas posibilidades textuales que ofrece la lectura en red, como por ejemplo los textos con imágenes -estáticas o en movimiento-, hipertextos-vínculos con otras páginas web-, gráficos, representaciones, números, pictogramas, colores, entre otras opciones (Fraca de Barrera, 2009), también representan mayores oportunidades, por ejemplo, para que un estudiante con discapacidad intelectual comprenda y acceda de mejor manera a la información escrita. Por lo tanto, la tecnología debe estar nutrida y diversificada en términos de contenidos y materiales, de modo que cada contenido escrito que se publique debería compatibilizarse con formatos accesibles, ya sea lengua de señas, audio y textos accesibles, de modo que cada persona, de acuerdo con su preferencia, capacidad o interés, pueda transitar en igualdad de condiciones por el mundo de la globalización y la comunicación. 
Estudios Pedagógicos XLV, № 3: 239-260, 2019

POLÍTICAS PÚBLICAS EN TORNO AL FOMENTO LECTOR Y PERSONAS EN SITUACIÓN DE DISCAPACIDAD: UNA

APROXIMACIÓN A LA LECTURA ESTÉTICA INCLUSIVA EN CHILE

\section{REFERENCIAS BIBLIOGRÁFICAS}

Bergna, M. (2010). Porque no tenemos que ser iguales, libros para integrarnos. Nuevas Hojas de Lectura: Lectura, discapacidad e inclusión.

Bisquerra, R. (2009). Metodología de la investigación educativa. Madrid: La Muralla.

Boote, D. \& Beile, P. (2005). Scholars before Researchers: On the Centrality of the Dissertation Literature Review in Research Preparation. Educational Researcher, 34(6), 3-15. Recuperado desde: https://doi.org/10.3102/0013189X034006003.

Bravo Valdivieso, L. (2011). Algunos Modelos de Investigación y las Teorías sobre los Trastornos del Aprendizaje de la Lectura. Psykhe, 9(2), 95-105.

Bravo Valdivieso, L., Milicic Müller, N., Cuadro, A., Mejía, L. \& Eslava, J. (2009). Trastornos del Aprendizaje: investigaciones psicológicas y psicopedagógicasen diversos paises de Sudamérica. Ciencias Psicológicas, 3(2), 203-218. Recuperado desde: http://www.scielo.edu.uy/pdf/cp/ v3n2/v3n2a09.pdf.

Cáceres, P. (2003). Análisis cualitativo de contenido: una alternativa metodológica alcanzable. Psicoperspectivas, II, 58-82. Recuperado desde: https://www.redalyc.org/articulo. oa? id=171018074008.

Castillo, A. (2015). Conceptualizaciones en torno a la lectura y escritura que poseen educadoras diferenciales de las regiones VIII, IX y X región de Chile y las competencias en estas destrezas que poseen estudiantes en situación de discapacidad intelectual. (Tesis Doctoral). España, UNED.

CNCA. (2006). Política Nacional del Libro y la Lectura. Santiago de Chile: Consejo Nacional del Libro y la Lectura.

(2010). Plan Nacional de Fomento de la Lectura Lee Chile Lee. Santiago de Chile: Consejo Nacional de la Cultura y las Artes y Consejo Nacional del Libro y la Lectura.

(2015). Política Nacional de la Lectura y el Libro 2015-2020. Santiago de Chile: Consejo Nacional de la Cultura y las Artes y Consejo Nacional del Libro y la Lectura.

CNCA, MINEDUC y DIBAM. (2015). Plan Nacional de la Lectura 2015-2020. Santiago de Chile: Gobierno de Chile.

Cordón García, J. A. (2016). La investigación sobre lectura en el entorno digital. MÉI: Métodos de información, 7(13), 247-268. Recuperado desde: http://www.metodosdeinformacion.es/mei/ index.php/mei/article/view/821/921.

Correa, P. \& Coll, A. (2011). Los mapas táctiles y diseño para todos los sentidos. Trilogía: CienciaTecnología-Sociedad, 22(32), 77-78.

Cox, C. (2007). Educación inclusiva y sociedad inclusiva. ¿Qué podemos hacer y qué podemos impulsar desde los sistemas educativos? Artículo presentado en el Taller Internacional sobre Educación Inclusiva, América Latina, Región Andina y Cono Sur. Buenos Aires.

Dezcallar, T., Clariana, M., Cladellas, R., Badia, M. \& Gotzens, C. (2014). La lectura por placer: su incidencia en el rendimiento académico, las horas de televisión y las horas de videojuegos. Ocnos, (12), 107-116. Recuperado desde: http://dx.doi.org/10.18239/ocnos_2014.12.05.

Echeita, G. \& Ainscow, M. (2011). La educación inclusiva como derecho. Marco de referencia y pautas de acción para el desarrollo de una revolución pendiente. Didáctica de la Lengua y la Literatura, (12), 26-46.

Fraca de Barrera, L. (2009). La lectura y el lector estratégicos: Hacia una tipologización ciberdiscursiva. Revista signos, 42(71), 431-446. recuperado desde: http://dx.doi.org/10.4067/ S0718-09342009000300006.

Gill, J. (2011). Hábitos lectores y competencias básicas en el alumnado de educación secundaria obligatoria. Educación XXI, 14(1), 117-134.

Herrera Fernández, V. (2014). Alfabetización y bilingüismo en aprendices visuales: Aportes desde las epistemologías de sordos. Educación y educadores, 17(1), 135-148. Recuperado desde: http:// educacionyeducadores.unisabana.edu.co/index.php/eye/article/view/3107. 
(2010). Estudio de la población Sorda en Chile: Evolución histórica y perspectivas lingüísticas, educativas y sociales. Revista Latinoamericana de Educación Inclusiva, 4(1), 211 226. Recuperado desde: http://repositoriocdpd.net:8080/handle/123456789/1916.

. (2009). En busca de un modelo educativo y de lectura coherente con las necesidades educativas especiales de los estudiantes sordos. Revista de Estudios y Experiencias en Educación, 8(16), 11-24. Recuperado desde: https://www.redalyc.org/articulo.oa?id=243116384001.

Jiménez, D. P. \& Flórez Romero, R. (2013). ¿La lectura y la literatura como derechos? El caso de la discapacidad intelectual. Revista de la Facultad de Medicina, 61(2), 91-99. Recuperado desde: https://revistas.unal.edu.co/index.php/revfacmed/article/view/39693/47359.

Jiménez, J., García, C., Bizama, M., Flores-Macías, R., Zambrano, R. \& Frugone, M. (2013). Un enfoque transcultural en el estudio de las dificultades de aprendizaje en lectura: los casos de España, Guatemala, Chile, Ecuador y México. Revista de Psicología y Educación, 8(2), 13-29.

Ley $\mathrm{N}^{\circ}$ 19227. (15 de Junio de 1993). Ley del fomento del libro y la lectura. Santiago, Chile: Gobierno de Chile.

Ley $\mathrm{N}^{\circ}$ 20422. (10 de Febrero de 2010). Ley que Establece Normas sobre Igualdad de Oportunidades e Inclusión Social de Personas con Discapacidad. Santiago, Chile: Gobierno de Chile.

Ley $\mathrm{N}^{\circ}$ 20845. (29 de Mayo de 2015). Ley de inclusión que regula la admisión de los y las estudiantes, eliminar el financiamiento compartido y prohíbe el lucro en establecimientos educacionales que reciben aporte del Estado. Santiago, Chile: Ministerio de Educación.

Lissi, M. R., Raglianti, Mirra, G. V., Salinas, M. \& Cabrera, I. (2011). Literacidad en Escolares Sordos Chilenos: Evaluación y Desafíos para la Investigación y la Educación. Psykhe, 12(2), 37-50. Recuperado desde: http://www.psykhe.cl/index.php/psykhe/article/view/359/339.

López Melero, M. (2011). Barreras que impiden la escuela inclusiva y algunas estrategias para construir una escuela sin exclusiones. Innovación Educativa, (21), 37-57.

López, F. (2002). El análisis de contenido como método de investigación. En clave pedagógica, 4, 169-179.

Marchant, T., Lucchini, G. \& Cuadrado, B. (2007). ¿Por qué Leer Bien es Importante?: Asociación del Dominio Lector con Otros Aprendizajes. Psykhe, 16(3), 3 - 16. Recuperado desde: http:// dx.doi.org/10.4067/S0718-22282007000200001.

Merino Risopatrón, C. (2011). La lectura literaria en la escuela. Horizontes Educacionales, 16(1), 49-61. Recuperado desde: https://www.redalyc.org/comocitar.oa?id=97922274005.

Miles, M. \& Huberman, M. (1994). Qualitative Inquiry and Research Design. Londres: SAGE Publications.

MINEDUC. (2017). Ley $N^{\circ} 21045$ Crea el ministerio de las culturas, las artes y el patrimonio. Santiago de Chile: Gobierno de Chile.

Ministerio de Educación Pública. (1990a). Decreto $N^{\circ} 86$ Aprueba planes y programas de estudio para atender niños con trastornos de la comunicación. Santiago de Chile.

. (1990b). Decreto $N^{\circ} 87$ Aprueba planes y programas de estudio para personas con deficiencia mental. Santiago de Chile: República de Chile.

. (1990c). Decreto $N^{\circ} 89$ Aprueba planes y programas de estudio para educandos con déficit visual. Santiago de Chile: República de Chile.

(1990d). Decreto $N^{\circ} 577$ Establece normas técnico pedagógicas para educandos con trastornos motores. Santiago de Chile: Gobierno de Chile.

(1990e). Decreto $N^{\circ} 815$ Establece normas técnico pedagógica para atender educandos con graves alteraciones en la capacidad de relación y comunicación que alteran su adaptación, comportamiento y desarrollo individual y aprueba planes y programa de estudio integral. Santiago de Chile: Gobierno de Chile.

Miranda, A. (2016). Alfabetización en lectura y escritura en personas en situación de discapacidad intelectual. Revista inclusiones, 3(1), 115-145. Recuperado desde: http://riberdis.cedd.net/ handle/11181/4806. 
Ocampo, A. (2016). ¿Cómo fomentar la lectura a niños y jóvenes con discapacidad intelectual?: desafíos desde la Educación Inclusiva y la Neurodidáctica. En: Educación Lectora, Fácil Lectura y Nuevas Identidades Educativas. Desafíos desde la inclusión y la interculturalidad. Santiago de Chile: Centro de Estudios Latinoamericanos de Educación Inclusiva: CELEI.

Orellana, P. \& Baldwin, P. (2016). Motivación y desempeño lector en niñas y niños chilenos: un estudio exploratorio. Educationis Momentum, 2(1), 7-28.

Palacios, A. (2008). El modelo social de discapacidad:orígenes, caracterización y plasmación en la Convención Internacional sobre los derechos de las personas con discapacidad. Madrid: Grupo editorial CINCA.

Parra, M. J. (2016). Práctica lectora y comprensión lectora. Estudio comparativo en dos instituciones escolares que incluyen niños con dificultades específicas del aprendizaje. En prensa.

Ramírez Leyva, E. M. (2009). ¿Qué es leer? ¿Qué es la lectura? Investigación bibliotecológica, 23(47), 161-188. Recuperado desde: http://www.scielo.org.mx/pdf/ib/v23n47/v23n47a7.pdf.

Ritchie, S. J. \& Bates, T. C. (2013). Enduring links from childhood mathematics and reading achievement to adult socioeconomics status. Psychological Science, 24(7), 1301-1308.

Rosenblatt, L. (1993). The transactional theory: Against dualisms. College English, 55(4), 377-386. . (1978). The reader, the text, the poem: The transactional theory of the literary work. En L. Rosenblatt, Literature as exploration. New York: Modern Language Associat.

Sanjuán Álvarez, M. (2011). De la experiencia de la lectura a la educación literaria. Análisis de los componentes emocionales de la lectura literaria en la infancia y la adolescencia. Ocnos: Revista de Estudios sobre Lectura, (7), 85-99. Recuperado desde: http://dx.doi.org/10.18239/ ocnos_2011.07.07.

Talanquer, V. (2014). Using Qualitative Analysis Software to Facilitate Qualitative Data Analysis. En D. Bunce, \& R. Cole, Tools of Chemistry Education Research (págs. 83-95). Washington DC: American Chemical Society.

Unidad de Curriculum y Evaluación. (2014). 20 años de las bibliotecas escolares CRA. Santiago de Chile : Ministerio de Educación.

Unidad de Educación Especial \& Fundación Down 21. (2008). Palabras + Palabras Aprendamos a Leer: Manual para las y los docentes. Santiago de Chile.

. (2012). Lectura Accesible y Clubes de Lectura. Santiago de Chile.

Valdés, M. (2013). ¿Leen en forma voluntaria y recreativa los niños que logran un buen nivel de Comprensión Lectora? Ocnos, 10, 71-89. Recuperado desde: http://dx.doi.org/10.18239/ ocnos_2013.10.04. 


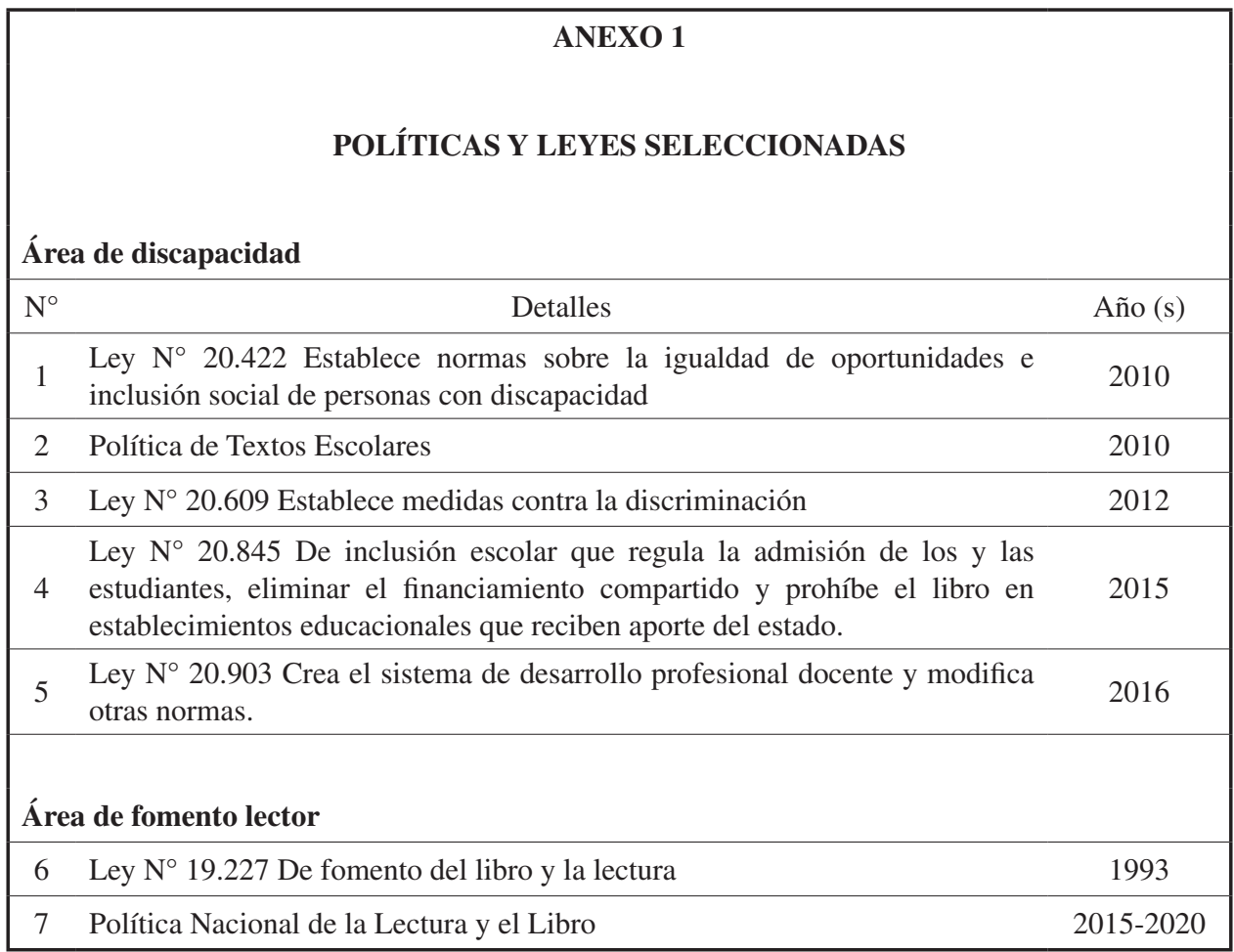




\begin{tabular}{|c|c|}
\hline & ANEXO 2 \\
\hline & $\begin{array}{l}\text { ERFIL ACADÉMICO Y ÁREAS DE ESPECIALIZACIÓN } \\
\text { DE LOS INFORMANTES ENTREVISTADOS }\end{array}$ \\
\hline Experto 1 (E1) & $\begin{array}{l}\text { Miembro del Equipo de Cedeti (PUC) que diseña e investiga respecto de } \\
\text { tecnologías inclusivas; posee estudios de posgrado tanto en discapacidad } \\
\text { como literatura en Inglaterra. }\end{array}$ \\
\hline Experto 2 (E2) & $\begin{array}{l}\text { Miembro del equipo de textos escolares de lenguaje en el Ministerio de } \\
\text { Educación; posee estudios de posgrado en curriculum y evaluación. }\end{array}$ \\
\hline Experto 3 (E3) & $\begin{array}{l}\text { Miembro del equipo de investigación del programa Bibliotecas Escolares } \\
\text { : CRA del Ministerio de Educación; con estudios de posgrado en literatura } \\
\text { en Francia. }\end{array}$ \\
\hline Experto 4 (E4) & $\begin{array}{l}\text { Coordina desde el Ministerio de Educación el Plan Nacional de Lectura; } \\
\text { : con amplia trayectoria en fomento lector tanto a nivel nacional e } \\
\text { internacional. }\end{array}$ \\
\hline Experto 5 (E5) & $\begin{array}{l}\text { Coordina la unidad de educación especial del Ministerio de Educación, con } \\
\text { amplia trayectoria en discapacidad a nivel nacional. }\end{array}$ \\
\hline Experto 6 (E6) & $\begin{array}{l}\text { Directora de una reconocida biblioteca en la ciudad de Santiago; con amplia } \\
\text { trayectoria en fomento lector tanto a nivel nacional como internacional. }\end{array}$ \\
\hline Experto 7 (E7) & $\begin{array}{l}\text { Editora Braille de la biblioteca central para ciegos, posee formación tanto } \\
\text { en lenguaje y comunicación como en discapacidad visual. }\end{array}$ \\
\hline Experto 8 (E8) & $\begin{array}{l}\text { Coordina desde la DIBAM el Plan Nacional de la Lectura; con amplia } \\
\text { trayectoria en fomento lector a nivel nacional. }\end{array}$ \\
\hline Experto 9 (E9) & $\begin{array}{l}\text { : Académico de la Pontificia Universidad Católica de Chile, con posgrados } \\
\text { en literatura y amplia trayectoria en discapacidad visual. }\end{array}$ \\
\hline Experto 10 (E10) & $\begin{array}{l}\text { Miembro del equipo del área educativa del Servicio Nacional de la } \\
\text { Discapacidad en Chile. }\end{array}$ \\
\hline Experto 11 (E11) & $\begin{array}{l}\text { Coordina el concurso de proyectos del fondo del libro del Consejo Nacional } \\
\text { de la Cultura y las Artes. }\end{array}$ \\
\hline Experto 12 (E12) & $\begin{array}{l}\text { Coordina desde el Consejo Nacional de la Cultura y las Artes el Plan } \\
\text { Nacional de la Lectura; con amplia trayectoria en fomento lector. }\end{array}$ \\
\hline Experto 13 (E13) & $\begin{array}{l}\text { Académica de la Pontificia Universidad Católica de Chile y representante } \\
\text { : en el centro Down UC; con amplia trayectoria en educación y discapacidad } \\
\text { intelectual. }\end{array}$ \\
\hline
\end{tabular}

